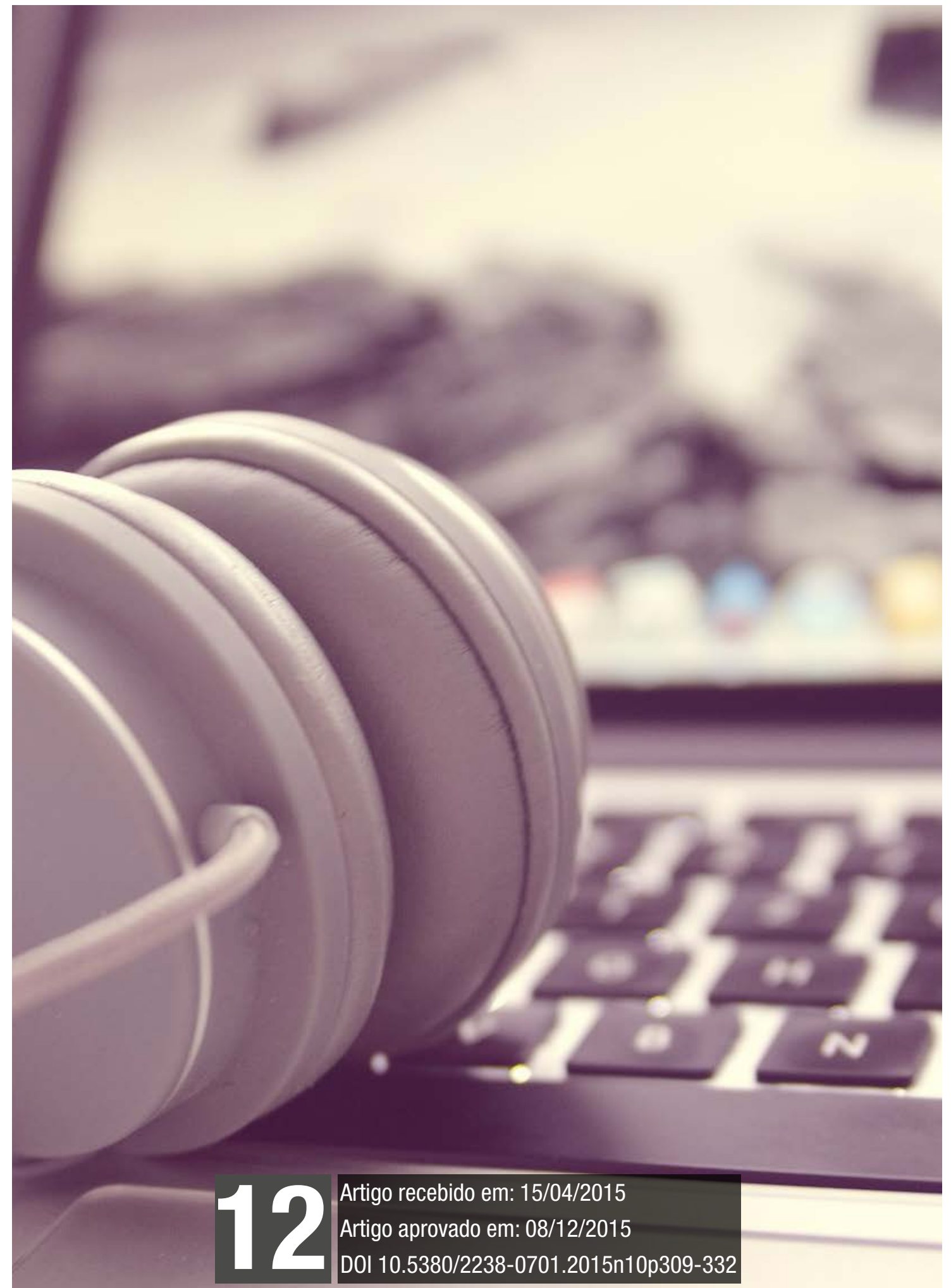


AÇÃO MIDIÁTICA, n. 10. Ju/Dez. 2015. Curitiba. PPGCOM-UFPR. ISSN 2238-0701 


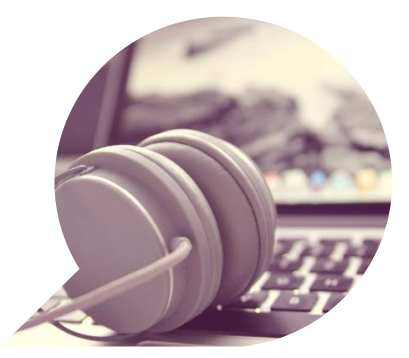

\section{Politicamente (in)correto:}

o humor de "Porta dos Fundos"

como disparador de conversações políticas online

Politically (in)correct: the humor in "Porta dos Fundos" as trigger of online political talks

Politicamente (in)correcto: el humor de "Porta dos Fundos" como detonante de las conversaciones politicas online

\begin{tabular}{c}
\hline BRUNO MENEZES A. GUIMARÃES $^{*}$ \\
\hline RENNAN LANNA MARTINS MAFRA $^{* *}$ \\
\hline
\end{tabular}

Resumo: $\mathrm{O}$ artigo objetiva examinar a relação entre humor e conversações cotidianas (everyday political talks) na internet. De modo mais específico, propomos examinar o potencial político do vídeo "Quem", do canal de humor "Porta dos Fundos". A base teórica está fundamentada em autores que discutem noções de deliberação e controvérsias deliberativas que se abrem para a conversação informal online. A metodologia empregada envolve descrição objetiva e sistemática do vídeo seguida de

\footnotetext{
* Mestrando em Comunicação pela Universidade Federal de Minas Gerais (UFMG) e bolsista da Coordenação de Aperfeiçoamento de Pessoal de Nível Superior (CAPES). E-mail: brunomenezesag@gmail.com.

* Doutor em Comunicação pela Universidade Federal de Minas Gerais (UFMG) e professor do Departamento de Comunicação Social da Universidade Federal de Viçosa (UFV). E-mail: rennan. mafra@gmail.com.
} 
análise do conteúdo de comentários a fim de entender em que medida a produção é capaz de disparar conversações nos contextos online. Como principais resultados, compreende-se que o conteúdo do vídeo é capaz de ampliar pontos de vista e de permitir a expressão de livres questões e temas publicamente relevantes, além de colaborar com o aprendizado democrático e com possibilidades de contestação e controvérsias públicas.

Palavras-chave: Everyday political talks; Conversação política; Humor; Internet; Porta dos Fundos.

Abstract: This article aims to examine the relationship between humor and everyday political talks on the internet. In a more specific way, we suggest the political potential analysis of the video "Quem", from the humor channel "Porta dos Fundos". The theoretical basis is founded on authors who discuss deliberation and deliberative controversies in the informal online conversation. The research methodology involves objective and systematic description of the video followed by the comment's content analysis in order to understand to which extent the production is capable to fire online conversations. As main results, it is understood that the video's content is able to broaden points of view and it allows the free expression of public relevant matters, as well as collaborating with the democratic learning and the possibilities of objection and public controversy.

Keywords: Everyday political talks; Political talk; Humor; Internet; Porta dos Fundos.

Resumen: El artículo tiene como objetivo examinar la relación entre humor $y$ conversaciones cotidianas (everyday political talks) en Internet. En concreto, nos proponemos examinar el potencial político de video "Quem", del canal de humor "Porta dos Fundos". La base teórica se basa en autores que hablan de la determinación de las nociones y controversias deliberativos que se abren para la conversación informal online. La metodología consiste en una descripción sistemática y objetiva del vídeo seguido de un análisis del contenido de los comentarios con el fin de comprender la medida en que la producción es capaz de disparar conversaciones en contextos online. Como principales 
resultados, se entiende que el contenido de vídeo es capaz de ampliar puntos de vista y permitir públicamente la libre expresión de cuestiones y temas pertinentes, así como los que colaboran con el aprendizaje democrático y con las posibilidades de contestación y controversia pública.

Palabras clave: Conversación política diária; Conversación política; Humor; Internet; Porta dos Fundos. 


\section{Introdução}

O tema proposto para discussão neste artigo está centrado em reflexões sobre as conversações cotidianas (everyday political talks), assuntos políticos deflagradas no âmbito da internet e nas possibilidades de ampliação de tais discussões nos contextos das complexas e pluralistas sociedades contemporâneas. De modo específico, pretendemos problematizar em que medida um vídeo de humor é capaz de engatilhar conversações acerca de temas políticos sem aparentemente prestar-se a tal finalidade, isto é, propomos examinar o potencial político do humor como disparador de conversações online capazes de ampliar pontos de vista e de permitir a expressão livre de problemas, questões e temas publicamente relevantes, de modo a colaborar com o aprendizado democrático, com as possibilidades de contestação e de produção de controvérsias públicas nos contextos sociais das democracias contemporâneas.

Historicamente, o humor sempre esteve comprometido com o questionamento de temas polêmicos de diferentes sociedades e épocas. Para o historiador francês George Minois (2003), o humor, e consequentemente o riso, são "efetivos instrumentos intelectuais da crítica" (MINOIS, 2003, p. 363) que, assim como diversos setores e movimentos, acompanhou o desenvolvimento de uma consciência social coletiva cada vez mais reflexiva. Esse humor, satírico e irônico, interessa diretamente para o desenvolvimento do artigo. Um humor que, quando difundido, propõe uma ressignificação de sentidos, isto é, desafia uma lógica instituída no que diz respeito, sobretudo, a temas políticos.

O universo empírico que tornou possível a investigação da problemática em questão refere-se ao canal de humor para o YouTube, "Porta dos Fundos". As tentativas de analisar o humor publicado em espaços virtuais de grande visibilidade e investigar seu potencial disparador de conversas políticas online são pouco realizadas. Uma busca por estudos desse tipo nos principais periódicos nacionais e internacionais aponta para uma escassez de análises integradoras de tais abordagens. Contudo, é possível classificar os estudos separadamente e compreender, mesmo que de forma preliminar, quais são as principais problemáticas acadêmicas acerca do humor na internet e de conversações cotidianas.

A produção acadêmica acerca do humor em si é vasta. Alocada no campo dos estudos linguísticos, diversos autores dedicaram suas 
pesquisas a essa temática. As análises giram em torno da construção do discurso humorístico nos mais variados objetos, como charges de jornais e revistas, quadrinhos, programas de televisão, livros de ficção, entre outros (SALIBA, 2002). Em suma, a tônica principal das pesquisas e das teorias sobre o humor indica a preocupação dos autores em entender as condições necessárias para a existência do discurso humorístico (PROPP 1992; BERGSON, 2004; POSSENTI, 2013). Contudo, a busca nos revela poucos estudos voltados para vídeos de humor na internet. Além disso, a maioria desses estudos é filiada às escolas de linguística aplicada, com poucas (ou quase nenhuma) referências à comunicação como campo científico capaz de fornecer explicações acerca de pessoas em interações constantes.

Por outro lado, as pesquisas voltadas para análises de conversações cotidianas políticas - ou não - em ambientes virtuais são mais amplas. A tendência dos autores que trabalham esse assunto é a de dividir, por meio de suas análises, as conversações em dois âmbitos distintos: (i) conversação sociável e (ii) conversação política. No âmbito social, isto é, ocasional, espontâneo, sem agenda definida e objetivos específicos, a força da conversação está no potencial de não reificação da cultura, porém raramente é observada na web por se tratar de uma prática comumente realizada pessoalmente (KIM, 2008; MARQUES, 2009; MAIA, 2012; ZHANG, 2014). Já a conversação política visa modificar preferências e resolver conflitos. Esse segundo âmbito é mais observável na internet, além de ser considerado o tipo de conversação válida para a deliberação (MAIA, 2012; GRAHAM, 2014; PETRIC, 2014). Nossos esforços estão concentrados em não somente analisar o aspecto propulsionador político de conversações que, em via de regra, são "não políticas", mas o de associá-las ao humor como gatilho disparador de todo esse processo publicamente engendrado.

Nesse sentido, o objetivo desse artigo é o de lançar luz à forma como o entretenimento do canal de humor "Porta dos Fundos" provoca conversações acerca de temas políticos, sem aparentemente prestar-se a tal função. De modo mais específico, nosso esforço é o de analisar a atuação de usuários do YouTube que tornam públicas suas opiniões por meio de comentários em busca de compreender em que medida as conversações cotidianas (everyday political talks) nesse espaço são engatilhadas de modo a fazer cidadãos ordinários conectados em rede falarem sobre temas políticos caros ao modo como conduzem suas vidas, uns em relação aos outros. 
Para isso, iniciaremos uma discussão teórica sobre o conceito de deliberação e, em seguida, sobre controvérsias deliberativas que porventura minimizam a rigidez de alguns princípios normativos por creditarem à comunicação na deliberação um aspecto mais fluído. Em um segundo momento, o diálogo se faz com autores que defendem a importância de conversações cotidianas para a manutenção da democracia, uma vez que a prática é entendida como exercício cívico. A união das duas primeiras seções revela o quanto a conversação pode servir a alguns dos anseios da deliberação e como pode emergir em sites de relacionamento na internet. Por fim, analisaremos como o vídeo “Quem” é responsável por provocar uma série de comentários na página do YouTube onde está hospedado. Desses comentários, faremos diferenciação entre quais deles possuem caráter conversacional político e o que tal conversa diz sobre os atores envolvidos (e os espaços de materialização de seus discursos), bem como sobre as capacidades do entretenimento humorístico de provocar a conversação política online.

\section{Deliberação e controvérsias deliberativas}

Em nossa sociedade complexa e plural, as tentativas de resolução de conflitos existentes entre determinadas parcelas da sociedade e o Estado podem se tornar motivo de conflitos ainda mais amplos, uma vez que chegar a um acordo entre as partes não é tarefa fácil. A teoria deliberativa, uma perspectiva da teoria democrática, propõese a olhar para vários desses problemas no intuito de solucioná-los de modo satisfatório para ambas as partes envolvidas. John Rawls e Jürgen Habermas foram os primeiros a fornecer uma estrutura teórica para constituição do "paradigma deliberativo". A teoria recebeu ênfase nos anos 90 e suas ideias influenciaram diversas pesquisas ao longo do tempo. O termo "deliberar" permite duas designações: ponderar (refletir) e decidir (resolver), isto é, envolve a busca para a solução de problemas e alcance do entendimento (MARQUES, 2009). De acordo com o processo deliberativo, tal busca é interativa e só pode ser conduzida juntamente com outras pessoas, ou seja, o processo de deliberação baseia-se no debate coletivo e na troca argumentativa em torno de determinadas questões.

Maia (2012) entende que o processo de deliberação possui "ligação direta sobre a decisão dos participantes, com base nos conceitos 
de justificação, por meio de discussão pública e raciocínio entre cidadãos iguais, pressuposto para gerar legitimidade em um processo que leva à formação de opinião e de vontade política"' (MAIA, 2012, p. 15, tradução nossa). O exercício deliberativo constitui-se, nesse sentido, como uma troca de argumentos orientada pela expectativa de que os envolvidos irão apresentá-los e que os demais irão compreendê-los (GUTMANN; THOMPSON, 2004). Nota-se, então, que o processo deliberativo possui um poder "educativo" em potencial, ou seja, torna as pessoas mais sensíveis às falas do outro e cria nos sujeitos a capacidade de ouvir o que cada um tem a dizer. De semelhante modo, também revela ser portador de um "senso comunitário" muito grande, uma vez que os indivíduos se tornam cientes de que sua participação só será efetiva mediante a participação do outro (MARQUES, 2013). É a partir de tais premissas que os processos de deliberação pública são capazes de aperfeiçoar a democracia.

Os estudos clássicos acerca de processos deliberativos apontam que é necessário haver inclusão de todos os afetados por determinado problema a fim de que a deliberação seja bem sucedida (HABERMAS, 1997). Além disso, espera-se dos participantes envolvidos uma fala sincera e respeito mútuo durante todo o processo (COHEN, 1997). Todavia, o processo deliberativo, segundo tais princípios, é passível de uma série de críticas devido ao caráter rígido de certos padrões. Maia cita alguns dos princípios normativos da deliberação elaborados por Habermas na tentativa opô-los a uma abordagem sistêmica mais fluída. Constituem a base dos princípios normativos:

a) expectativa de que os participantes irão questionar e transcender qualquer que seja a sua preferência inicial (principalmente devido ao impacto dos argumentos); b) plena inclusão de todos aqueles que podem ser afetados por uma decisão; c) igualdade entre os participantes, considerados como pessoas livres e iguais; d) interação livre e não forçada; e) ausência de restrições quanto a temas e contribuições dadas nos tópicos de discussões; $\mathrm{f}$ ) possibilidade de reverter resultados quando necessário (MAIA, 2012, p. 16, tradução nossa) ${ }^{2}$.

1 Trecho original em inglês: It involves decision binding on participants, based on the concepts of justification through public argument and reasoning among equal citizens, which is supposed to generate legitimacy through a procedure that leads to the formation of opinion and political will (MAIA, 2012, p. 15).

2 Trecho original em inglês: a) an expectation that participants will rationally question and transcend whatever their initial preference has been (mainly because of the impact of arguments); b) full inclusion of all those who might be affected by a decision; c) equality among participants, considered as free and equal persons; d) free and unforced interaction; e) no 
A abordagem sistêmica é uma forma de incluir na deliberação as mais diversas maneiras de se comunicar com o intuito de tornar as possíveis tomadas de decisão mais inclusivas e democráticas. Maia dialoga com demais autores ${ }^{3}$ para refletir acerca da racionalidade prevista em Habermas e, dentro do possível, expandir os pontos de vista sobre a deliberação. Os autores defendem que a racionalidade habermasiana, repetidamente questionada, exclui fatores igualmente importantes para a deliberação, como a emoção, a retórica, testemunhos, saudações, narrativas e histórias de vida. Nesse sentido, tais estudiosos mostram-se preocupados com a questão da argumentação crítica que faz com que a linguagem utilizada nos debates seja hegemônica e que reflita apenas interesses de determinada classe social dominante.

A alegação de que o modelo deliberativo é demasiadamente racionalista é oriundo da oposição histórica entre "razão" e "emoção". Todavia, a emoção presente nos atos de fala não é oposta ao processo de percepção cognitiva dos sujeitos, tampouco é um mero sentimento capaz de privar os indivíduos de razão durante a argumentação. Em determinados casos, a emoção é fundamental para perceber questões específicas e, até mesmo, entendê-las como questões morais. Os propósitos de Maia em considerar a emoção como elemento importante para a deliberação pública faz coro com os nossos. A autora diz que considerar a emoção "ajuda a abrir portas para a compreensão da complexidade dos ambientes de mídia de massa e para desenvolver os diferentes níveis nos quais emoções e o processo de raciocínio podem ser explorados" (MAIA, 2012, p. 19, tradução nossa) ${ }^{4}$.

Do ponto de vista da deliberação clássica, a retórica é igualmente vista como portadora de insumos capazes de minar um discurso racional. Alguns deliberacionistas a rejeitam porque, na maioria das vezes, ela passa a ser entendida como convencimento coercitivo que pode vencer demais argumentos existentes. Entretanto, a retórica pode ser útil ao passo que alguns discursos apenas são levados em conta mediante a estruturação de uma fala capaz de guiá-los a um

restrictions regarding topics and topical contributions; f) the possibility of reversing outcomes (MAIA, 2012, p. 16).

3 Chantal Mouffe (2005), Iris Young (1996), Lynn Sanders (1997), Wayne Gabardi (2001), Dryzek (2000), entre outros.

4 Trecho original em inglês: [...] consideration of emotion helps open the door to an understanding of the complexity of the mass media environment and to developing the various levels on which the above connections between emotions and the process of reasoning can be explored (MAIA, 2012, p. 19). 
alto grau de atenção por parte dos envolvidos. A questão dos testemunhos (MAIA; GARCÊZ, 2013), narrativas e histórias de vida pode ser, nesse sentido, também considerada: as narrativas podem ajudar a articular alguns dos sentimentos de injustiça de modo a permitir que os sujeitos expressem a si mesmos - e, consequentemente, compreendam a si mesmos -, com relação a pressões sofridas, humilhações e explorações cotidianas.

As considerações a respeito da emoção, retórica e narrativas (testemunhos, histórias de vida) ajudam-nos a pensar a deliberação como um sistema ampliado (HENDRIKS, 2006; MANDSBRIGDE, 2009), um pouco mais aberto e fluído. A necessidade de se pensar o processo dessa maneira origina-se de uma série de críticas ao racionalismo habermasiano que desconsidera algumas oposições clássicas e históricas entre "interesses coletivos" e "interesses privados" durante os debates. Dar voz a grupos não hegemônicos e entender - e considerar - as formas pelas quais tais vozes se materializam faz parte dos esforços descortinados nos estudos recentes de deliberacionistas. Por esse motivo, na próxima seção vamos discutir a importância de conversações cotidianas. Nosso objetivo final será analisar a forma como o vídeo "Quem" dispara discussões online nas quais os sujeitos falam sobre política de forma direta e indireta, dialogadas entre si ou não, tudo isso sem agenda específica.

\section{Conversação informal online e deliberação}

Por ora, identificaremos o papel desempenhado por mídias digitais na relação estabelecida entre "tornar pública" determinada opinião e as implicações disso em sistemas deliberativos. Após as discussões sobre deliberação, interessa-nos as conversações cotidianas - ou discussões políticas de todos os dias ${ }^{5}$. Aqui, chamamos atenção para a importância dos "media" para o fomento de tais conversações. A conversação informal é realizada por cidadãos ordinários, geralmente em espaços de convívio privado ou semi-público, entre pessoas com algum laço de união, seja afetivo ou familiar. Maia (2008) afirma que:

50 termo utilizado em inglês é "everyday political talk". Para fins didáticos, usaremos como tradução do termo "conversações cotidianas" sem a intenção de empobrecê-lo, tampouco utilizálo de forma incorreta. 
[...] a conversação e a discussão permanente entre cidadãos e grupos ativistas são fundamentais para sustentar o debate público, a fim de processar os problemas tal como eles surgem na sociedade; para ponderar acerca de desacordos morais inevitáveis na vida política e, assim, encontrar os melhores meios de lidar com eles; para promover os interesses dos cidadãos, visando a configuração de políticas públicas; e, ainda, para exercer um controle democrático da agenda política e vigilância sobre a ação dos representantes (MAIA, 2008, p. 199).

As formas como cidadãos produzem e reproduzem razões capazes de guiar um debate público são os principais interesses de uma série de pesquisadores que se voltam para as conversações cotidianas (MANSBRIDGE, 2009). Chama-nos a atenção o fato de que tais discussões políticas não seguem uma formatação clássica, isto é, um conjunto de padrões. Ao contrário, cidadãos comuns utilizam-se da palavra em ambientes não formais para exercer seus direitos de fala. A conversa entre os pares faz com que os envolvidos se sintam mais confortáveis frente à exposição de opiniões acerca de determinado assunto, pois não há a expectativa do constrangimento comum de situações formais (MAIA, 2008). Consequentemente, as conversações cotidianas tendem a ser mais triviais, fluídas e guiadas pelo simples prazer de estar frente ao outro e falar.

Logo, a principal contribuição das conversações cotidianas para sistemas deliberativos reside no fato de que os cidadãos ordinários descobrem que falar é importante e, por esse motivo, não se calam (GAMSON, 2011). Um motivo possível seria porque esse tipo de troca de falas não requer o cumprimento de procedimentos rígidos de interação necessários para a deliberação tal qual apontada na primeira seção. Contudo, isso não quer dizer que as conversações cotidianas não sirvam aos processos deliberativos. Alguns pesquisadores indicam, inclusive, a necessidade delas para alcançar um status de deliberação plena (MANSBRIDGE, 2009; MAIA, 2008). Também, as conversações cotidianas podem ser consideradas como um meio de tornar os processos políticos inteligíveis ao passo que contribuem para a descoberta de problemas da sociedade. Maia aponta que a "conversa tem sido considerada como um elemento crucial de qualquer cultura cívica e de uma democracia forte" (MAIA, 2012, p. 216, tradução nossa) ${ }^{6}$.

6 Trecho original em inglês: Indeed, talk has long been regarded as a crucial element of any civic culture and of a strong democracy" (MAIA, 2012, p. 216). 
Nesse sentido, processos deliberativos que se dão em espaços conversacionais informais são deflagrados e alimentados por uma série de motivações. Dentre elas, o humor pode se colocar como um aspecto disparador de conversações políticas, uma vez que, por si só, o humor "faz falar" e possui caráter relacional, ou seja, o sentido de algo risível só se constitui a partir do contato com o outro (BERGSON, 2004). Dito isso, o humor pode insinuar um potencial deliberativo na medida em que, na complexa trama relacional que engendra, pode tornar visíveis questões antes tomadas como pertencentes a esferas íntimas e (ou) privadas, ou mesmo alterar o status de temas tomados pelos sujeitos em suas redes cotidianas de conversação como pré-reflexivos ou pré-políticos.

Para Graham e Hajru (2011), democracia deliberativa envolve deliberação não somente no sentido de produzir razões orientadas ao bem comum e à tomada de decisões coletivas dentro de sistemas formais ou semiformais, mas, também, um processo de produção de raciocínio $^{7}$ público e acordos mútuos dentro de espaços comunicativos informais da esfera pública. $\mathrm{O}$ que os autores querem dizer é que as conversações cotidianas não são diminuídas por não serem direcionadas diretamente a ações e tomada de decisões políticas. Ao contrário, é por meio da participação na conversação cotidiana que "os cidadãos se tornam conscientes e informados, tentam compreender os outros, testam antigas e novas ideias, expressam, desenvolvem e transformam suas preferências e opiniões" (GRAHAM; HAJRU, 2011, p. 20, tradução nossa $)^{8}$. Em suma, é por meio das conversações cotidianas que os sujeitos - e, consequentemente, a sociedade - se abrem para ações políticas mais amplas.

Por meio da tessitura do que foi dito, temos que a conversação cotidiana é tida como uma importante prática cívica. Os sites de redes sociais servem aos cidadãos como espaços alternativos de conversações diárias nos quais cada pessoa se apropria de maneira específica. Nesse ponto, as diversas atitudes dos indivíduos conectados dialogam com as controvérsias deliberativas aqui listadas. Cada pessoa pode, de acordo com suas limitações e intenções, fazer conexões entre os assuntos abordados com experiências individuais e coletivas,

70 termo utilizado pelos autores é "reasoning".

8 Trecho original em inglês: It is through ongoing participation in everyday talk whereby citizens become aware and informed, try to understand others, test old and new ideas, and express, develop and transform their preferences and opinions (GRAHAM e HAJRU, 2011, p. 20). 
além de utilizar da emoção e de narrativas de vida. Contudo, o que gostaríamos de destacar é o caráter não deliberativo de alguns desses espaços. Não podemos generalizar e caracterizar todos os espaços online onde há possibilidade de interatividade entre usuários como espaços deliberativos. Na maioria dos casos, não há esse objetivo e as pessoas simplesmente comentam e exprimem opinião (de forma respeitosa ou não) sem o objetivo final de se chegar a um acordo mútuo.

Então, a internet se configura como espaço que propicia a fala. Todavia, as características de tais falas em ambientes virtuais são específicas. Diferentes sites estão disponíveis para cidadãos que queiram falar "com" e "para" o outro, além da possibilidade de mobilização de diversos tópicos de discussão. Em alguns casos, porém, muitos dos usuários são levados a falar (comentar) em tais ambientes com o propósito de, apenas, tornar pública determinada opinião ou sentimento, sem dirigi-los a alguém específico. Graham e Hajru (2011) desenvolveram um interessante estudo acerca do entretenimento como "disparador" de conversações cotidianas em ambientes virtuais. Os autores dedicaram-se a entender como a internet se torna uma extensão da esfera pública e, especificamente, como assuntos aparentemente triviais e não políticos geram uma conversação política.

A análise dos autores ajuda-nos a relacionar as conversações cotidianas com a dimensão política de espaços virtuais. A proposta inicial foi a de entender a cultura popular como parte da política, uma vez que as pessoas vivem por meio da cultura e os valores culturais operam na política. Em seguida, a pesquisa voltou-se para fóruns de discussão online a respeito de dois programas de reality TV do Reino Unido, "Big Brother UK" e "Wife Swap", na tentativa de mostrar como programas de entretenimento são capazes de impulsionar conversações cotidianas em ambientes virtuais a partir de episódios aparentemente apolíticos.

Acreditamos, portanto, na capacidade dos sites de redes sociais abrigarem conversações cotidianas acerca de temas políticos sem fins deliberativos, entretanto, com fortes capacidades de contribuição da não ossificação da opinião de cidadãos ordinários devido às conversações. Nossa próxima seção traz uma análise de como entretenimento brasileiro do canal "Porta dos Fundos", produzido para

9 Todd Graham e Auli Hajru, no texto "Reality TV as a trigger of everyday political talk in the net-based public sphere" desenvolvem a análise com base no entretenimento televisivo. 0 termo utilizado pelos autores é "trigger", aqui traduzido por "gatilho". 
a internet, contribui para despertar nos usuários a manifestação de opiniões e, por conseguinte, falas políticas. Nosso desejo é o de tentar mostrar que o humor provocativo de tal canal ironiza temas cotidianos da sociedade de modo a levar os espectadores à fala. A análise que segue buscará entender o que há de político em tais falas e quais são as possíveis implicações de todo esse contexto que mistura internet, humor e política. A metodologia utilizada parte de uma descrição objetiva e sistemática do vídeo seguida por uma análise de um número selecionado de comentários.

\section{Quem? Vídeo de humor como disparador de conversações políticas online}

Em 9 de junho de 2014, "Porta dos Fundos" lançou o vídeo "Quem". A produção possui dois minutos e cinco segundos de duração e possui mais de três milhões de visualizações e cerca de 2.500 comentários $^{10}$. Na descrição oficial do vídeo, lemos que "descrever alguém é sempre complicado. Como é possível reduzir os medos, os sonhos, as angústias e os paradigmas de uma pessoa a um ou outro adjetivo? Você aponta pra ela, tenta defini-la em uma palavra, mas não adianta. Alguém pode sair magoado". Logo, essa é a principal temática do vídeo. Os roteiristas e os produtores procuraram trazer à tona a forma como pessoas são despreparadas para lidar com questões de gênero, raça, limitações físicas ou psicológicas de outras pessoas, de modo a convidar os telespectadores a acompanhar uma dramatização situacional e introduzir novas formas de significações acerca daquilo que pode ser considerado politicamente correto ou incorreto. ${ }^{11}$

A esquete é ambientada em um bar. $\mathrm{O}$ efeito humorístico desejado é acionado logo nos primeiros segundos de vídeo, quando um

10 Os números exatos, datados do dia 07/12/2015 são: 3.724 .973 visualizações e 2.498 comentários. O vídeo "Quem", bem como os comentários na íntegra estão disponíveis em < http://goo.gl/NXAUQZ>.

11 A consolidação dos processos democráticos nos contextos contemporâneos, inevitavelmente, corresponde a um aumento da disputa de grupos e segmentos plurais no espaço público. Nesse sentido, o espaço público, entendido como o espaço do aparecimento e da visibilidade (ARENDT, 2007) passa a acolher uma complexa disputa por sentidos acerca do que se pode ou não dizer, daquilo que é certo ou não fazer, movimento esse que, por esses termos, convida uma determinada comunidade de linguagem (HABERMAS, 1997) a permanentemente refletir sobre o que é politicamente correto, digno de ser aceito como moralmente válido em determinado contexto de interações ou aquilo que é politicamente incorreto, e que por isso pode ter seus limites de significação inaceitáveis em determinado ambiente de interações historicamente constituído. 
homem pergunta a outro, que estava no balcão, acerca do gerente. Com a pergunta "quem é o gerente?", o rapaz do balcão precisa responder que se trata da pessoa negra um pouco mais à frente. Contudo, a resposta não é imediata, muito menos precisa. $\mathrm{O}$ jovem possui nítidas dificuldades de pronunciar a palavra "negro" e, de fato, não a pronuncia. No lugar, utiliza termos como "rapaz ali", "o único que...", "o menino", além de apontar para o gerente com o dedo diante da falta de adjetivos suficientes. Em seguida, o protagonista recebe outro questionamento sobre o gerente. A pergunta "como ele é?" incita ainda mais a necessidade de caracterização. Confuso e incomodado, o personagem responde que "ele é moreno". A resposta é rebatida com "mas todos ali são morenos...". A cena continua.

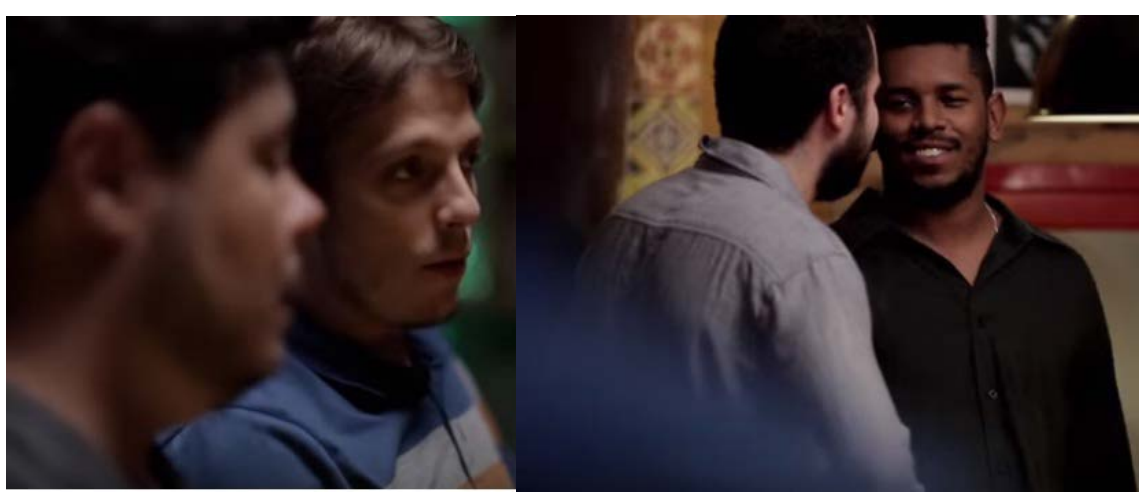

Figura 1: Homem do balcão que é indagado e o gerente do bar Fonte: <http://goo.gl/NXAUQZ>

O homem que deseja saber quem é o gerente tenta contornar a situação confusa e pergunta “quem está do lado do gerente?". Trata-se de um homem adulto anão, todavia, o ananismo também não é naturalmente descrito pelo personagem que o chama de "menino", "garoto" e "coisinha”. Irritado, afirma que tanto o gerente, quanto o anão, estão em um grupo em frente à dupla. Para acabar com as dúvidas, ele tentar esclarecer que o anão está do lado de outra pessoa, mas tamanha é sua surpresa ao descobrir que tal trata-se de uma travesti. Sem saber como descrever a travesti, ele pronuncia a indagação "ah, meu Deus, o que é aquilo ali?". A solução encontrada foi chamá-lo de "pessoa”. O quadro instaurado tende a provocar o riso justamente por retratar a dificuldade de alguém para lidar com gênero, cor da pele e diferença. 


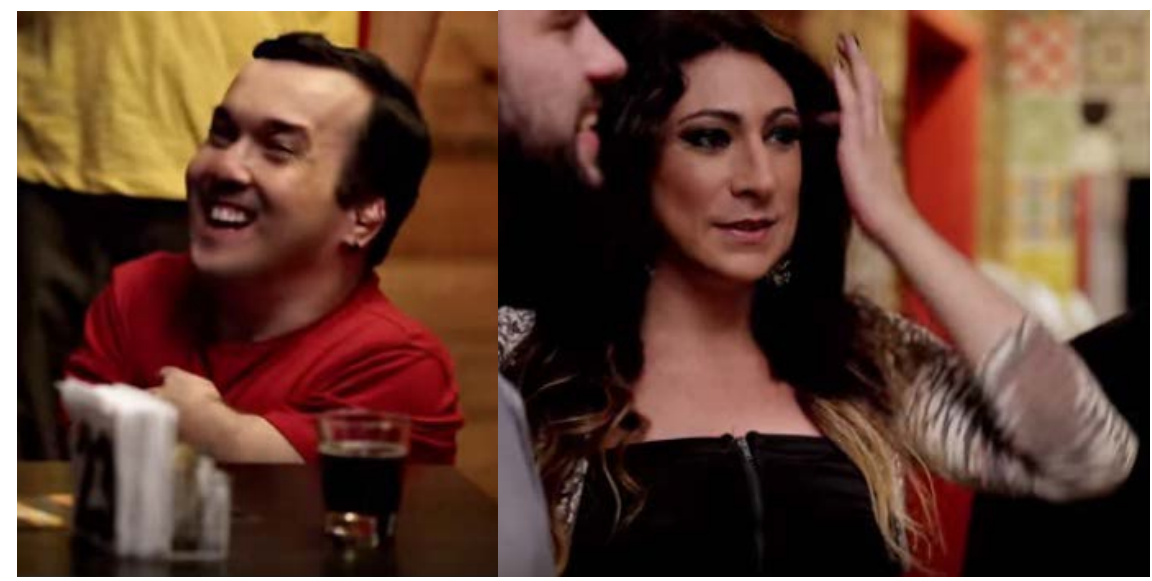

Figura 2: Homem anão e a travesti presentes em cena Fonte: <http://goo.gl/NXAUQZ>

O personagem que inicialmente queria saber quem era o gerente mostra-se estupefato e declara que aquela situação "está difícil". O protagonista, ao seu lado, suado e incomodado com aquele quadro, admite a dificuldade e prevê que a relação entre eles ficará ainda mais difícil, haja vista a chegada de um homem portador de deficiência física, locomovendo-se em uma cadeira de rodas. Ele questiona em voz alta “o que é isso que está acontecendo?", “é segregação?”. Ele se volta para o atendente do bar do outro lado do balcão e pede limão em sua bebida. $\mathrm{O}$ ato de virar as costas para o homem que gerou todo o desconforto ao perguntar quem era o gerente indica o rompimento da interação entre eles e, consequentemente, o fim do vídeo. A vinheta do canal encerra a esquete e abre espaço para os créditos finais.

Em linhas gerais, após a descrição dos momentos cômicos, percebemos a seriedade do assunto que foi tratado por "Porta dos Fundos". O que está em jogo é a forma como as pessoas se posicionam diante da diferença de outras e, ainda, a forma como tais pessoas se utilizam de caracterizações devidas e indevidas. Aparentemente, o entretenimento humorístico do canal tem por objetivo apenas provocar o riso. Contudo, nossos esforços estarão concentrados em olhar para parte dos comentários dos vídeos na página do YouTube para entender como o vídeo possui o poder de fazer com que diversas pessoas o relacione com questões políticas mais amplas, de modo a problematizá-las. 
Nossos interesses são sintetizados em três perguntas-chave: (i) em que proporção o humor de "Porta dos Fundos", especificamente o vídeo "Quem", propicia a conversação política no espaço reservado a comentários do YouTube? (ii) Quais as características de tal conversação? (iii) Qual o teor dos comentários que compartilham dos mesmos interesses e em que medida eles se diferenciam de comentários nitidamente avessos?

A primeira pergunta será respondida de forma quantitativa em um gráfico logo a seguir. Concentremo-nos nos dois últimos questionamentos. Certo comentário do "Usuário 1" (U1) 12 diz:

[U1] Gostei do vídeo. Demonstra como o coitadismo [sic] empregado muito nos faz por muitas vezes ter medo de ser preconceituoso, ainda que nada do que seja dito deva ser entendido como preconceito...

O comentário em questão desencadeou uma série de outros comentários diretos. De início, percebemos que o termo "preconceito" foi operador principal extraído do vídeo por parte do telespectador. O usuário 1 (U1) demonstrou que não há intenções preconceituosas retratadas no vídeo. $\mathrm{O}$ que há é uma vitimização por parte de grupos minoritários, cujo termo adotado foi "coitadismo". Notemos como se deu o processo interativo a partir do comentário de "U1":

[U2]: Preconceito é quando chama o negro de moreno...

[U3]: "U1", você deve sofrer por ser preconceituoso não?! Deve ser muito ruim mesmo não poder expor isso abertamente. Não é preconceito chamar um negro de negro, e não é "coitadismo" lutar contra o preconceito.

[U4]: É errado não gostar de ser chamado de preto ou crioulo, palavra pejorativa usada por donos de escravos e pessoas brancas, portuguesas e espanholas na época em que o Brasil foi colonizado? Dependendo do jeito que a pessoa fala e como ele se comporta perante essas situações nós, negros, que sofremos com descriminação, sabemos quais são as intenções da pessoa. "O moreninho ali.... Vai se $\mathrm{f}^{\star * * *}$ ao preconceito.

12 Todos os comentários foram retirados da página do YouTube e colados no espaço desse artigo. Nenhum conteúdo foi suprimido. Algumas revisões ortográficas foram feitas, haja vista que isso não compromete a análise. 0 caractere * é utilizado para suprimir palavras de baixo calão. 
[U5]: Então me expliquem como querem ser descritos. Se chamar de moreno é preconceito, se chamar de negro é preconceito, se chamar de preto é preconceito? Sou casado com uma negra e não vejo problema nenhum em chamá-la assim. Assim como me chamam de alemão. Parem de frescura!

[U6]. Segue tutorial de como chamar uma pessoa negra: Negro. Pronto, gente! Ninguém sabia? O que não pode é chamar de crioulo, preto, macaco por que são sim termos que remetem a um passado sofrimento e humilhação! Assim fica muito difícil. "U4" explica perfeitamente porque é errado usar certos tipos de nomes. "U5", não se faça de sonso.

[U1] "U3", interessante. De onde você tirou que sou preconceituoso mesmo? Porque em momento algum falei nada que expressasse isso. $\mathrm{O}$ que disse foi uma descrição do que se passa no vídeo e que muitas vezes ocorre no cenário real. Em muitos casos as pessoas têm medo de parecerem preconceituosas, ao descrever fisicamente um terceiro, ainda que tal descrição em tese não tenha nada de preconceituoso. Isso ocorre muito por conta de "coitadismos" sim, queira você ou não.

Façamos uma análise com foco na conversação selecionada. Percebemos que o comentário de U1 acerca da forma como o preconceito se faz presente na sociedade derivou-se da sua percepção do vídeo. $\mathrm{O}$ internauta assume uma posição um tanto quanto liberal a respeito da forma como os sujeitos tratam o próximo com relação às diferenças entre eles. U2, de forma contida, sente-se incomodado com o comentário de $\mathrm{U} 1 \mathrm{e}$, sem muitos argumentos, responde que a linha de raciocínio de U1 é preconceituosa desde a base, pois o verdadeiro preconceito consiste em omitir a palavra "negro" e trocá-la por "moreno". Em seguida, U3 também se sente intimado a falar diretamente para U1. O interessante da fala de U3 é a forma como ele apreende uma característica inerente ao espaço virtual em questão: a possibilidade de utilização de meios virtuais para exposição de ideias passíveis de repreensão quando dita face a face. U3 considera que U1 só falou (escreveu) o seu comentário devido à distância entre corpos propiciada pela internet.

A conversação continua e U4 surge com o objetivo de problematizar a origem dos termos utilizados no vídeo (e defendidos como não preconceituosos por U1). U4 afirma que o fato de alguém não gostar de ser chamado de "preto" ou "crioulo" pode ser devido à origem desses termos, o período da colonização. Nesta ocasião, cabe 
ressaltar que U4 não omite a cor da sua pele e afirma ser negro para justificar toda a sua argumentação, isto é, utilização de uma narrativa - exemplo pessoal - como justificativa para que a fala seja exposta tal como é. Também, U4 afirma já ter sofrido preconceito por ser negro e encerra sua fala com um xingamento a U1. Em meio às mensagens de desacordo com a fala principal, surge U5 que demonstra não discordar de U1, ao contrário, também se utiliza de exemplos pessoais para afirmar que não importa a forma de tratamento, tanto "moreno" quanto "negro" será visto como preconceito uma vez que a sociedade não está preparada para ambas as adjetivações.

U6 debate de forma direta. Segundo ele, "negro" é de fato o termo que deve ser usado em casos como esse. Os outros termos - citados no vídeo - são desautorizados pela fala de U6 pelos mesmos motivos citados por U4. Notemos que o fim de cada um dos três últimos comentários analisados é marcado por ofensas ou xingamentos diretos, o que pode prejudicar a aceitação da conversação entre os envolvidos. Contudo, a presença constante desse tipo de tratamento indica uma forte tendência de como se constituem as falas em ambientes virtuais, ou seja, o anonimato possível e a distância entre os sujeitos propiciam ataques diretos e falas agressivas para autoafirmação. Para encerrar, U1 retoma a fala e diz que discorda de ser chamado de preconceituoso pelo fato de apenas ter descrito o que o próprio vídeo exibe. A troca de mensagens não se encerra na segunda intervenção de U1, entretanto, optamos por pausar a análise nesse momento, já que o pequeno recorte já oferece respostas para os objetivos deste artigo.

O gráfico abaixo quantifica e classifica o conjunto total de comentários de modo a entender o "todo" que configura a página onde o vídeo "Quem" está hospedado: 


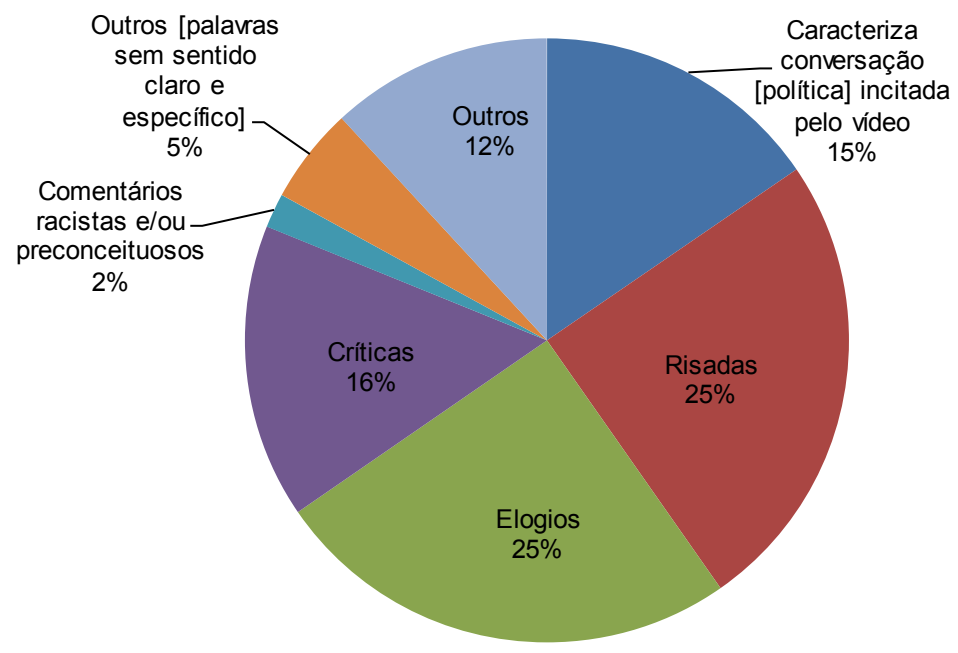

Figura 3: Gráfico de classificação dos comentários Fonte: Elaboração nossa

O gráfico parte da quantidade total de comentários - 2.543 - e os classifica segundo categorias específicas. Nota-se, portanto, que o universo de comentários é amplo e as características das falas postadas são variadas. A maioria delas é risadas (25\%), elogios ao vídeo (25\%) e críticas à produção (16\%). Também há ocorrência, mesmo que pequena, de comentários racistas e preconceituosos escritos por usuários anônimos ou fakes ${ }^{13}(2 \%)$, bem como comentários que possuem ligação com o vídeo, mas não revelam pertinência ou sentido específico (5\%). Comentários que nada tem a ver com o vídeo equivalem a $12 \%$ do total, índice relativamente alto. Interessa-nos aqui que comentários de teor político engatilhado pelo vídeo equivalem a $15 \%$ do total postado na página. O número engloba tanto os comentários individuais que deram início a conversações, quanto as respostas a esses comentários. É perceptível, então, a contribuição do humor de "Porta dos Fundos" para fazer falar cidadãos ordinários no exercício do status telespectadores e usuários do YouTube.

130 termo designa usuários que assumem uma identidade ao postar determinado comentário, contudo, tal identidade não corresponde à pessoa de fato. 


\section{Considerações finais}

O presente artigo preocupou-se em analisar a presença de conversações políticas online no YouTube. A principal contribuição é a de afirmar a condição do humor - especificamente do humor realizado por "Porta dos Fundos" - de disparar conversações políticas na internet. $\mathrm{O}$ gráfico, de caráter quantitativo, ofereceu um panorama da constituição da página de comentários em torno do vídeo "Quem" e indicou que dentre críticas, elogios, risadas e conteúdos sem ligação direta com o vídeo, há um número expressivo de falas que associam a produção com questões de ordem política mais amplas, capazes de afetar um número expressivos de sujeitos. O resultado de tal afetação é o engajamento em falas sem aparente caráter deliberativo, mesmo porque o espaço não se propõe a isso, mas dotada de um teor cívico e democrático considerável, uma vez que diferentes sujeitos, cada um ao seu modo, trazem à tona suas opiniões acerca de preconceito e racismo.

Com vistas à breve análise de caráter qualitativo, feita com base em um número selecionado de comentários, constatamos algumas características da conversação pela internet. Da forma como foi apreendida, detectamos que as falas não estão preocupadas com a questão da reciprocidade, uma vez que o anonimato e a distância física entre os corpos permitem comentários carregados de certo teor agressivo e de autoafirmação. A conversação pela internet também propicia a aparição de opiniões mais dissonantes, diferentes de espaços públicos formais com presença de poucas pessoas. Em outras palavras, ambientes privados ou semi-públicos propiciam ajuntamento de pessoas que compartilham de raciocínios e interesses semelhantes. Esse controle não é possível na internet, já que o espaço é livre e qualquer pessoa pode lançar mão da palavra, da forma como preferir. Prosseguiremos nos esforços de analisar as conversações na internet e as implicações desses fenômenos. Cremos, portanto, que as conclusões aqui podem ser úteis para trabalhos futuros.

\section{Referências}

BERGSON, H. O riso: ensaio sobre a significação da comicidade. São Paulo: Martins Fontes, 2004. 
COHEN, J. Deliberation and democractic legitimacy. In: BOHMAN, J. e REIGH, W. (Orgs). Deliberative democracy. Cambridge-Mass: MIT Press, 1997. p. 67-91.

GAMSON, W. Falando de Política. Belo Horizonte: Autêntica, 2011.

GRAHAM, T.; HARJU, A. Reality TV as a trigger of everyday political talk in the net-based public sphere. European Journal of Communication, 2011, 26(1), 18-32.

GUTMANN, A.; THOMPSON, D. What deliberative democracy means. In: . Why deliberative democracy? New Jersey: Princeton University Press, 2004, p. 1-63.

HABERMAS, J. Actions, speech acts, linguistically mediated interactions, and the lifeworld. In: Cooke, M. (ed.). Jürgen Habermas: On the pragmatics of communication. Cambridge, MA: MIT Press, 1998, p. 215-255.

HABERMAS, J. Política deliberativa: um conceito procedimental de democracia. In: HABERMAS, J. Direito e Democracia: entre faticidade e validade. Rio de Janeiro: Tempo Brasileiro, 1997. p. 9-56.

ARENDT, Hannah. A condição humana. 10ed. Rio de Janeiro: Forense Universitária, 2007.

HENDRIKS, C. Integrated deliberation: reconciling civil society's dual role in deliberative democracy. In: Political Studies, 2006, v. 54, p. 486-508.

MAIA, R. C. M. Conversação cotidiana e deliberação. In: GOMES, W.; MAIA, R. C. M. In: Comunicação e democracia: problemas e perspectivas. Belo Horizonte: Paulus, 2008, p. 195-219.

. Deliberative democracy: approaching normative controversies. In: Deliberation, the media and political talk. New York: Hampton Press, 2012, p. 13-58. 
. From public sphere to deliberative system: locating the place of the media. In: Deliberation, the media and political talk. New York: Hampton Press, 2012, p. 59-76.

. Political talk and democratic deliberation. In: Deliberation, the media and political talk. New York: Hampton Press, 2012, p. 211-225.

. Mídia e deliberação. Rio de Janeiro: Editora FGV, 2008.

MAIA, R. C. M.; GARCÊZ, R. L. O. Recognition, feelings of injustice and claim justification: a case study of deaf people's storytelling on the internet. European Political Science Review, v. 1, p. 1-24, 2013.

MANSBRIDGE, J. A conversação cotidiana no sistema deliberativo. In: MARQUES, A. (org.). A deliberação pública e suas dimensões políticas e comunicativas: textos fundamentais. Belo Horizonte: Autêntica, 2009.

MARQUES, A. (org.). A deliberação pública e suas dimensões políticas e comunicativas: textos fundamentais. Belo Horizonte: Autêntica, 2009.

MARQUES, A. A ética do discurso e a formação do sujeito político em Habermas. Cadernos da Escola do Legislativo, Volume 5, número 23, jan./jun. 2013, p. 161-183.

MINOIS, G. História do riso e do escárnio. São Paulo: Editora Unesp, 2003.

POSSENTI, S. Humor, língua e discurso. São Paulo: Editora Contexto, 2013.

PROPP, V. Comicidade e riso. São Paulo: Editora Ática S.A., 1992.

SALIBA, E. T. Raízes do riso. A representação humorística brasileira: da Belle Époque aos primeiros tempos do rádio. São Paulo: Editora Companhia das Letras, 2002. 